\title{
INFLUÊNCIA DAS CARACTERÍSTICAS ANATÔMICAS E DO TEOR DE EXTRATIVOS TOTAIS DA MADEIRA DE Eucalyptus grandis W. Hill ex Maiden NA QUALIDADE DA COLAGEM
}

\author{
INFLUENCE OF ANATOMICAL FEATURES AND EXTRACTIVES CONTENT WOOD OF \\ Eucalyptus grandis W. Hill ex Maiden IN QUALITY BONDING
}

\author{
Vanessa Cristina do Sacramento Albino ${ }^{1}$ Fábio Akira Mori ${ }^{2}$ Lourival Marin Mendes ${ }^{3}$
}

\begin{abstract}
RESUMO
O trabalho teve como objetivo caracterizar anatomicamente e quantificar os extrativos totais em diferentes posições de toras de Eucalyptus grandis W. Hill ex Maiden com 18 anos de idade e avaliar a influência dessas características sobre a resistência ao cisalhamento e percentagem de falhas na madeira de juntas coladas com adesivo termoendurecedor resorcinol-formaldeído. Foram preparadas lâminas histológicas para o estudo anatômico e determinou-se o teor de extrativos totais. A preparação das juntas coladas foi feita de acordo com a norma ASTM D 2339-98(2000). Utilizou-se o coeficiente de correlação de Pearson, a $1 \%$ de probabilidade pelo teste $t$ de Student, para avaliar as correlações existentes entre as características anatômicas e teor de extrativos com a qualidade das juntas coladas. Verificou-se que houve correlação entre resistência ao cisalhamento com as seguintes características: diâmetro do vaso, espessura da parede, largura e comprimento da fibra, largura do raio e teor de extrativos totais. E, em relação à percentagem de falhas na madeira, houve correlação entre esta com as seguintes características: frequência de vasos, espessura do lume da fibra, frequência e altura do raio. Tanto no sentido radial quanto no sentido longitudinal das toras, houve variação dos valores encontrados para a mensuração dos elementos anatômicos, quantidade de extrativos totais, resistência ao cisalhamento e percentagem de falhas na madeira.
\end{abstract}

Palavras-chave: anatomia da madeira; teor de extrativos; qualidade da colagem.

\begin{abstract}
The study aimed to anatomically characterize and to quantify the total extractives in different positions of the log of Eucalyptus grandis W. Hill ex Maiden with 18 years of age and to assess their influence on the shear strength and percentage of wood failure in adhesive bonded joints with thermosetting resorcinolformaldehyde. Histological slides were prepared for an anatomical study and determined the total extractive content. The preparation of bonded joints was made according to ASTM D 2339-98(2000). It was used the correlation coefficient of Pearson, $1 \%$ probability by t test to evaluate the correlation between the anatomical and extractives content with the quality of the glued joints. It was found that there was a correlation between the shear strength with the following characteristics: vessel diameter, wall width, length and width of the fiber, the width of the radius and total extractives content. For the percentage of wood failure, there was a correlation between this with the following characteristics: the frequency of vessels, thickness of the heat of fiber, and high frequency of lightning. Both the radial direction as in the longitudinal direction of the logs there was change in the values found for the measurement of the anatomical elements, the total amount of extractives, the shear test strength and the percentage of wood failure.
\end{abstract}

Keywords: wood anatomy; extractive contents; quality of bonding.

1. Engenheira Florestal, Mestre em Ciência e Tecnologia da Madeira, Universidade Federal de Lavras, Caixa Postal 3037, CEP 37200-000, Lavras (MG). vanessa.floresta@hotmail.com

2. Engenheiro Florestal, Dr., Professor Associado do Departamento de Ciências Florestais, Universidade Federal de Lavras, Caixa Postal 3037, CEP 37200-000, Lavras (MG). morif@ufla.br

3. Engenheiro Florestal, Dr., Professor Adjunto do Departamento de Ciências Florestais, Universidade Federal de Lavras, Caixa Postal 3037, CEP 37200-000, Lavras (MG). lourival@ufla.br

Recebido para publicação em 22/07/2010 e aceito em 23/08/2011 


\section{INTRODUÇÃO}

A aplicação da madeira, cada vez maior nas construções civis e nas indústrias de móveis, faz com que a procura por produtos de maior valor agregado aumente a cada dia. E, para suprir essa demanda, as áreas de florestas plantadas vêm aumentando a cada ano. Em 2008 estas áreas acumularam no Brasil o total estimado de 6.126 .000 ha com eucalipto e pinus. A área correspondente às florestas de eucalipto foi de 69,5 \% (4.258.704 ha) (Associação Brasileira de Produtores de Florestas Plantadas ABRAF, 2009).

$\mathrm{O}$ sucesso alcançado pelas indústrias florestais, a cada tempo, se deve aos esforços dos pesquisadores. Várias pesquisas estão sendo feitas para viabilizar industrialmente a madeira do eucalipto, já que essa vem ocupando posição de destaque no setor florestal brasileiro.

Os produtos reconstituídos de madeira têm sua importância no setor florestal e, segundo Marra (1992), são fabricados através da colagem de lâminas, tábuas, sarrafos, partículas ou fibras, com dimensões e características definidas em função de suas aplicações finais. O balanço estrutural do produto é conferido através da ligação adesiva entre os elementos de madeira, sua distribuição e orientação na estrutura do composto. Percebe-se, neste contexto, a grande necessidade de informações relacionadas às características da madeira e suas influências na colagem.

Alguns estudos já foram feitos para se conhecer o comportamento diante da colagem de espécies do gênero Eucalyptus, como de: Famer (1972); Della Lucia e Vital (1981;1989); Nascimento et al. (2001); Serpa (2001); Vital et al. (2006); Lobão e Gomes (2006); Lima et al. (2008).

Outro fator que se deve levar em consideração é o adesivo utilizado na colagem. Em componentes estruturais, o adesivo resorcinolformaldeído é muito utilizado, uma vez que ele confere às juntas coladas alta resistência mecânica, elevada resistência à água e à temperatura. Porém, é um adesivo que possui custo elevado, o que leva a propor alternativas, como por exemplo, o emprego do mesmo em madeiras de reflorestamento e de menor valor, o que pode fazer com que o custo final do produto seja menor. Por isso, torna-se de grande importância conhecer e estudar o comportamento deste adesivo em madeira do gênero Eucalyptus.

O processo de colagem é influenciado pelas propriedades anatômicas da madeira e, segundo
Marra (1992), a relevância está voltada aos seus efeitos no movimento do adesivo para o interior da estrutura da madeira, ou seja, relativo à penetração. Dentre as principais características anatômicas da madeira que influenciam a colagem, podem-se citar: os anéis de crescimento (lenho inicial e tardio), percentagem de cerne e alburno, lenhos de reação, grã, porosidade, fibra, parênquima, raios e tiloses.

A estrutura diferenciada dos anéis de crescimento pode ocasionar problemas relativos à penetração de adesivos à linha de cola "faminta" ou "espessa", o que é contornável pela alteração na formulação do adesivo (IWAKIRI, 2005). O cerne, em relação ao alburno, é menos permeável, possuindo maiores dificuldades na secagem e na absorção de produtos, como adesivos (BURGER e RICHTER, 1991). A presença de madeira juvenil por sua menor densidade, menor percentagem de lenho tardio e elementos fibrosos de menor comprimento com paredes mais finas, com menor conteúdo de celulose, também pode interferir no processo de adesão (VITAL et al., 2006).

Os constituintes químicos da madeira também podem interferir no processo de colagem. E, em relação aos extrativos, sua presença, quantidade e tipo podem afetar a adesão. Pesquisas têm mostrado que os extrativos na superfície da madeira são os principais contribuidores para a inativação da superfície, gerando assim um pobre umedecimento do adesivo. Os adesivos utilizados em madeira, na sua maioria, usam a água como carreador, gerando assim problemas de umedecimento, fluxo e penetração na superfície coberta pelo extrativo (SKEIST, 1990; FOREST PRODUCTS LABORATORY, 1999). Outra influência do extrativo se dá na alteração do $\mathrm{pH}$ da superfície da madeira.

O trabalho teve como objetivo caracterizar anatomicamente e quantificar o teor de extrativos totais em diferentes posições de toras de Eucalyptus grandis W. Hill ex Maiden e avaliar a influência dessas características sobre a resistência ao cisalhamento e percentagem de falhas na madeira em juntas coladas com adesivo termoendurecedor resorcinol- formaldeído.

\section{MATERIAL E MÉTODOS}

\section{Material de estudo e caracterização da área}

Utilizou-se madeira de Eucalyptus grandis W. Hill ex Maiden, proveniente de duas árvores cultivadas no município de Lavras, MG. As árvores apresentavam 18 anos de idade e diâmetro médio de 
$23 \mathrm{~cm}$ a $1,30 \mathrm{~m}$ do solo.

A cidade de Lavras, no Sul de Minas, localiza-se nas coordenadas $21^{\circ} 14^{\prime} \mathrm{S}$ de latitude e longitude $45^{\circ} 00^{\prime} \mathrm{W}$, à altitude média de $900 \mathrm{~m}$. A precipitação média anual está em torno de $1.400 \mathrm{~mm}$ e a temperatura média anual é de $19,4^{\circ} \mathrm{C}$. A área de plantio possui relevo declivoso, com predominância de solo podzólico. O plantio foi feito em covas, com espaçamento de $2 \times 2 \mathrm{~m}$. Na área realizaram-se desbastes sucessivos e corte seletivo.

\section{Obtenção das tábuas}

De cada árvore retirou-se uma tora com 4 metros de comprimento, sendo este obtido a partir da base da árvore. As toras foram processadas na forma de tábuas com espessuras médias de $25 \mathrm{~mm}$ conforme mostrado na Figura 1. Foram obtidas amostras próximas à medula $(\mathrm{A})$, próximas à casca (C) e à região intermediária (B). Tais amostras foram secas ao ar livre e após a secagem foram cortadas em três posições adjacentes, considerandose o sentido longitudinal da tora, a partir do qual se obteve tábuas com 1,3 metros de comprimento que foram consideradas como posição I (região próxima à base da árvore), posição II e posição III.

Das tábuas obtidas foram retiradas amostras de $20 \mathrm{~cm}$ nas extremidades que foram destinadas à caracterização anatômica e à análise do teor de extrativos totais da madeira.

\section{Caracterização anatômica e determinação do teor de extrativos totais}

Para confecção de lâminas permanentes, foram obtidos corpos de prova orientados nos planos transversal, longitudinal radial e tangencial, nas dimensões de 1 x 1 x $1 \mathrm{~cm}$. Após o amolecimento em água, procedeu-se o seccionamento em micrótomo de deslizamento modelo Jung SM 2000, com espessura variando de 14 a $16 \mu \mathrm{m}$. As seções foram coradas com corante safranina $(1 \% \mathrm{p} / \mathrm{v})$, sendo posteriormente desidratadas em série alcoólica ascendente, e embebidas gradativamente em acetato de butila (soluções de álcool: acetato de butila, 3:1, 1:1, 1:3 e acetato de butila p.a.) e, após serem aparadas, foram fixadas em lâminas permanentes com o adesivo Entellan ${ }^{\circledR}$. A metodologia utilizada na confecção das lâminas permanentes foi a descrita por Burger e Richter (1991).

Para o preparo de lâminas provisórias, foi efetuado o desmembramento dos tecidos componentes da madeira, através de uma solução macerante de peróxido de hidrogênio e ácido acético $1 \mathrm{~N}$, na proporção de $1: 1(\mathrm{v} / \mathrm{v})$. As lâminas foram preparadas com glicerina e o material histológico, corado com corante safranina, de acordo com o Método de Franklin (FRANKLIN, 1945).

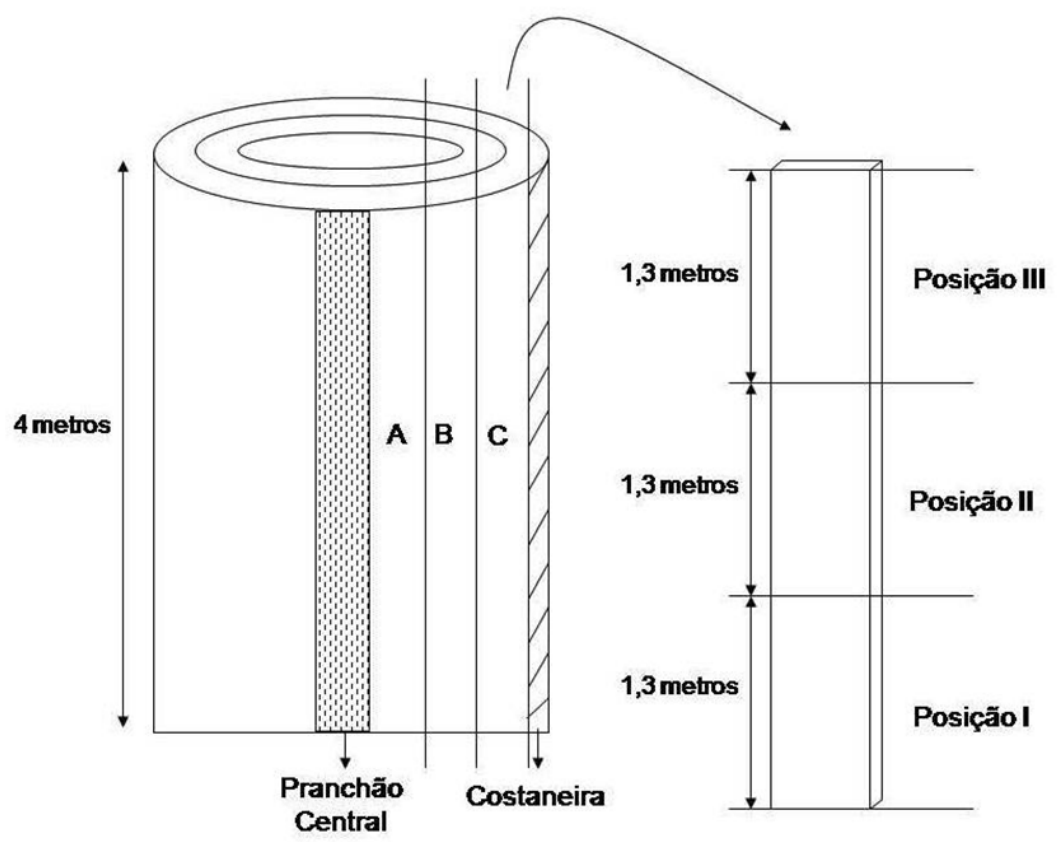

FIGURA 1: Esquema de obtenção das tábuas, em que "A" se refere à região próxima à medula; "B" à região intermediária e "C" à região próxima à casca.

FIGURE 1: Scheme for obtaining the boards, where " $A$ " refers to a region close to the pith, " $B$ " to the intermediate region and " $\mathrm{C}$ " to the region next to the bark. 
Foram mensurados o comprimento e a largura das fibras, espessura da parede, diâmetro e frequência dos vasos, altura, largura e frequência dos raios, de acordo com a norma International Association of Wood Anatomists - IAWA (1989); utilizando-se um software de análise de imagem (Wincell-Pro).

A determinação do teor de extrativos totais foi feita de acordo com a norma ABTCP M 3/69 (ASSOCIAÇÃO BRASILEIRA TÉCNICA DE CELULOSE E PAPEL-ABTCP, 1974). A serragem foi moída em moinho de martelo, e classificadas em peneiras de 40 e 60 mesh, utilizando-se a serragem que ficou retida na peneira de 60 mesh. A umidade da serragem em base seca foi determinada para que pudesse ser utilizado o peso absolutamente seco da madeira, na determinação do teor de extrativos totais. Foram realizadas duas repetições por amostra, perfazendo um total de 36 amostras.

\section{Confeç̧ão e avaliação das juntas coladas}

As tábuas obtidas foram processadas na forma de sarrafos, nas dimensões de $0,5 \times 10$ x $30 \mathrm{~cm}$ (espessura x largura x comprimento), destinados à preparação das juntas coladas de acordo com a norma ASTM D 2339-98 (ASTM, 2000). Os sarrafos obtidos foram acondicionados em uma câmara de climatização a $25 \pm 2{ }^{\circ} \mathrm{C}$ de temperatura a $60 \pm 2 \%$ de umidade relativa, para posterior colagem, ficando os sarrafos com umidade média em torno de $12 \%$.

$\mathrm{O}$ adesivo termoendurecedor utilizado foi $\mathrm{o}$ resorcinol-formaldeído (Cascophen-RS-216) com teor de sólidos de $60 \%$, viscosidade de $5500 \mathrm{cP}$, pH de 7,1 e tempo de endurecimento de 8 horas, aproximadamente. Adicionou-se endurecedor (preparado endurecedor FM), na proporção de uma para cinco partes de adesivo resorcinolformaldeído.

A gramatura do adesivo utilizada foi de $250 \mathrm{~g} / \mathrm{m}^{2}$ aplicado em face dupla. O adesivo foi preparado previamente antes de seu emprego e espalhado sobre as superfícies com auxílio de um pincel. As juntas foram imediatamente fechadas e, assim, permaneceram por aproximadamente 15 minutos, sendo, então, prensadas a frio a $12 \mathrm{kgf} / \mathrm{cm}^{2}$ durante 24 horas. Confeccionou-se 36 pares de juntas coladas para cada árvore, correspondentes às combinações entre posição radial, posição longitudinal e três repetições de cada junta colada.

Após a colagem, as juntas foram novamente acondicionadas na câmara de climatização, nas mesmas condições já citadas, por aproximadamente 15 dias e então foram desdobradas em 12 corpos de prova cada uma. Foram realizados testes de resistência ao cisalhamento nos corpos de prova em uma máquina pneumática de ensaio marca Contenco-Pavitest Cisalhamento na Colagem 1.01-0, modelo I 4230, instalada no Laboratório de Adesão e Adesivos, na Unidade Experimental de Produção de Painéis de Madeira DCF-UFLA, Lavras, MG. Após a ruptura, quatro pessoas da área de Ciência e Tecnologia da Madeira inspecionaram todos os corpos de prova, com o auxílio de uma lâmina reticulada, para a quantificação da percentagem de falhas na madeira. As avaliações da percentagem de falhas na madeira foram julgadas pela ASTM D-3110 (ASTM, 1994).

\section{Análise estatística dos dados}

As análises estatísticas foram realizadas utilizando-se o software SAEG 9.1. Foram avaliadas as correlações existentes entre as características anatômicas e o teor de extrativos totais com a qualidade das juntas coladas (resistência ao cisalhamento e percentagem de falhas na madeira) com o adesivo resorcinol-formaldeído. Utilizou-se o coeficiente de correlação de Pearson, a $1 \%$ de probabilidade pelo teste tde Student. Confeccionouse 36 pares de juntas para cada árvore, resultado de um delineamento fatorial completo do tipo $3 \times 3 \times$ 3 , correspondentes às combinações entre posição radial, posição longitudinal e três repetições para cada junta colada.

\section{RESULTADOS E DISCUSSÃO}

\section{Características anatômicas, teor de extrativos totais, resistência ao cisalhamento e percentagem de falhas na madeira nas diferentes posições da tora}

$\mathrm{Na}$ Tabela 1 estão apresentados os valores médios e o coeficiente de variação para as características anatômicas, teor de extrativos totais, resistência ao cisalhamento e percentagem de falhas na madeira para a posição radial das toras da madeira de Eucalyptus grandis W. Hill ex Maiden.

$\mathrm{Na}$ Tabela 2 estão apresentados os valores médios e o coeficiente de variação para as características anatômicas, teor de extrativos totais, resistência ao cisalhamento e percentagem de falhas na madeira para a posição longitudinal das toras da madeira de Eucalyptus grandis. 
TABELA 1: Valores médios para as características anatômicas, teor de extrativos totais, resistência ao cisalhamento e percentagem de falhas na madeira para a posição radial das toras da madeira de Eucalyptus grandis.

TABLE 1: Mean values for the anatomical characteristics, content of extractives, shear strength and percentage of failures in the wood for the radial position of the logs of Eucalyptus grandis.

\begin{tabular}{lcccccc}
\hline \multirow{2}{*}{ Parâmetros } & \multicolumn{2}{c}{ Medula } & \multicolumn{2}{c}{ Intermediária } & \multicolumn{2}{c}{ Casca } \\
\cline { 2 - 7 } & Média & $\mathrm{CV}(\%)$ & Média & $\mathrm{CV}(\%)$ & Média & $\mathrm{CV}(\%)$ \\
\hline Largura de fibra $(\mu \mathrm{m})$ & 16,30 & 19,50 & 16,10 & 18,09 & 17,04 & 20,47 \\
Espessura de parede $(\mu \mathrm{m})$ & 4,47 & 25,52 & 4,43 & 24,86 & 5,23 & 23,74 \\
Espessura do lume $(\mu \mathrm{m})$ & 7,36 & 31,52 & 7,24 & 33,63 & 6,58 & 37,16 \\
Comprimento de Fibra $(\mathrm{mm})$ & 1,16 & 17,43 & 1,15 & 15,33 & 1,25 & 15,73 \\
Frequência de Vasos $\left(\mathrm{vasos} / \mathrm{mm}^{2}\right)$ & 2,08 & 33,16 & 1,63 & 26,77 & 1,50 & 28,31 \\
Diâmetro do vaso $(\mu \mathrm{m})$ & 155,85 & 21,96 & 167,93 & 17,46 & 191,55 & 26,04 \\
Altura do raio $(\mathrm{mm})$ & 0,21 & 31,12 & 0,21 & 31,24 & 0,20 & 34,60 \\
Largura do raio $(\mu \mathrm{m})$ & 8,04 & 28,42 & 7,71 & 32,13 & 8,47 & 32,42 \\
Frequência de raio $($ raios/mm) & 1,89 & 15,73 & 1,83 & 18,06 & 1,76 & 14,88 \\
Teor de extrativos totais $(\%)$ & 6,10 & 11,45 & 6,62 & 5,91 & 8,84 & 6,49 \\
\hline Resistência ao cisalhamento $(\mathrm{Mpa})$ & 3,81 & 16,64 & 4,72 & 10,99 & 5,73 & 10,42 \\
Percentagem de falha na madeira $(\%)$ & 97,15 & 28,71 & 93,04 & 12,35 & 76,96 & 34,19 \\
\hline
\end{tabular}

Em que: $\mathrm{CV}=$ coeficiente de variação.

TABELA 2: Valores médios para as características anatômicas, teor de extrativos totais, resistência ao cisalhamento e percentagem de falhas na madeira para a posição longitudinal das toras da madeira de Eucalyptus grandis.

TABLE 2: Mean values for the anatomical characteristics, content of extractives, shear strength and percentage of failures in the wood for the longitudinal position of the logs of Eucalyptus grandis.

\begin{tabular}{lcccccc}
\hline \multirow{2}{*}{ Parâmetros } & \multicolumn{2}{c}{ Base } & \multicolumn{2}{c}{ Meio } & \multicolumn{2}{c}{ Topo } \\
\cline { 2 - 7 } & Média & CV $(\%)$ & Média & CV $(\%)$ & Média & CV(\%) \\
\hline Largura de fibra $(\mu \mathrm{m})$ & 16,57 & 19,63 & 16,26 & 18,43 & 16,60 & 20,01 \\
Espessura de parede $(\mu \mathrm{m})$ & 4,96 & 25,28 & 4,45 & 22,70 & 4,72 & 26,14 \\
Espessura do lume $(\mu \mathrm{m})$ & 6,65 & 37,00 & 7,36 & 29,25 & 7,17 & 36,06 \\
Comprimento de Fibra $(\mathrm{mm})$ & 1,19 & 15,70 & 1,16 & 16,61 & 1,21 & 16,17 \\
Frequência de Vasos $($ vasos/mm $)$ & 1,73 & 29,07 & 1,82 & 29,63 & 1,65 & 29,54 \\
Diâmetro do vaso $(\mu \mathrm{m})$ & 170,31 & 21,47 & 167,24 & 26,99 & 177,77 & 17,00 \\
Altura do raio $(\mathrm{mm})$ & 0,21 & 30,96 & 0,21 & 31,93 & 0,21 & 34,07 \\
Largura do raio $(\mu \mathrm{m})$ & 8,35 & 33,84 & 8,05 & 31,08 & 7,84 & 28,06 \\
Frequência de raio $($ raios/mm) & 1,75 & 18,57 & 1,92 & 14,95 & 1,80 & 15,16 \\
Teor de extrativos totais $(\%)$ & 7,56 & 13,21 & 6,02 & 6,39 & 7,98 & 4,25 \\
\hline Resistência ao cisalhamento $(\mathrm{Mpa})$ & 4,82 & 13,96 & 4,78 & 11,58 & 4,67 & 12,52 \\
Percentagem de falha na madeira $(\%)$ & 84,22 & 37,79 & 90,09 & 14,51 & 92,84 & 22,96 \\
\hline
\end{tabular}

Em que: $\mathrm{CV}=$ coeficiente de variação. 
A largura média das fibras no sentido radial foi maior na casca $(17,04 \mu \mathrm{m})$, e no sentido longitudinal foi menor na posição II $(16,26 \mu \mathrm{m})$, sendo classificadas como estreitas. No sentido radial, a espessura média de parede das fibras foi maior na casca $(5,23 \mu \mathrm{m})$ e no sentido longitudinal foi menor na posição II $(4,45 \mu \mathrm{m})$, classificada como média. A espessura média do lume das fibras decresceu no sentido medula-casca variando de 7,36 a $6,58 \mu \mathrm{m}$ e no sentido longitudinal foi menor na posição I $(6,65 \mu \mathrm{m})$. O comprimento médio das fibras no sentido radial foi maior na posição próxima à casca $(1,25 \mathrm{~mm})$ e no sentido longitudinal foi menor na posição II $(1,16 \mu \mathrm{m})$, classificado como curtas. O diâmetro médio do vaso aumentou no sentido medula-casca variando de 155,85 a $191,55 \mu \mathrm{m}$ e no sentido longitudinal foi menor na posição II $(167,24 \mu \mathrm{m})$, classificado como médio. A frequência de vaso decresceu no sentido medula-casca variando de 2,08 a 1,50 vasos $/ \mathrm{mm}^{2}$ e no sentido longitudinal foi menor na posição III da tora $\left(1,65\right.$ vasos $\left./ \mathrm{mm}^{2}\right)$, classificada como poucos. Não houve variação da altura dos raios nos sentidos radial e longitudinal, sendo classificados como extremamente baixos. No sentido radial a largura do raio foi menor na posição intermediária $(7,71 \mu \mathrm{m}) \mathrm{e}$ no sentido posição I-posição III houve decréscimo variando de 8,35 a $7,84 \mu \mathrm{m}$, classificados como extremamente finos. A frequência média do raio no sentido radial foi menor na posição próxima à casca $(1,76 \mathrm{raios} / \mathrm{mm})$ e no sentido longitudinal foi menor na posição I (1,75 raios/mm), classificada como pouco numerosos. Todas as classificações seguiram a norma International Association of Wood Anatomists - IAWA (1989).

Tomazello Filho (1985) estudando a estrutura anatômica de oito espécies de eucalipto encontrou para a espécie Eucalyptus grandis aos dez anos de idade, frequência de vaso de 7 vasos/ $\mathrm{mm}^{2}$, diâmetro tangencial do vaso igual a $111 \mu \mathrm{m}$, frequência de raios de 9 raios $/ \mathrm{mm}$, altura média do raio de $0,20 \mathrm{~mm}$, largura média do raio igual a 14 $\mu \mathrm{m}$, comprimento de fibras igual a $1,2 \mathrm{~mm}$, largura de fibra igual a $23 \mu \mathrm{m}$, espessura da parede média igual a $5,4 \mu \mathrm{m}$ e diâmetro do lume igual a 12,2 $\mu \mathrm{m}$. Os valores encontrados por este autor, com exceção da altura do raio, foram, no geral, maiores dos encontrados neste trabalho. Tal fato pode ter ocorrido devido à diferença de idade da espécie estudada e diferentes condições edafoclimáticas.

Em relação ao teor de extrativos totais, no sentido radial, houve um acréscimo no sentido medula-casca, variando de 6,10 a $8,84 \%$. E no sentido longitudinal o maior valor encontrado foi na posição III da tora $(7,98 \%)$. Os valores médios encontrados estão em conformidade com o normalmente relatado na literatura usual, como em Silva et al. (2005). Silva et al. (2005), estudando a influência da idade e da posição ao longo do tronco na composição química da madeira de Eucalyptus grandis, encontraram que o teor de extrativos totais apresentou tendência de crescimento em relação à posição do disco ao longo do tronco, no sentido base-topo.

No sentido radial os valores médios da resistência ao cisalhamento aumentaram no sentido medula-casca variando de 3,81 a 5,73 Mpa. E no sentido longitudinal decresceu no sentido posição I-posição III variando de 4,82 a 4,67 Mpa. Em relação à percentagem de falhas na madeira esta foi menor na posição próxima à casca $(76,96 \%) \mathrm{e}$ no sentido longitudinal houve aumento no sentido posição I-posição III da tora variando de 84,22 a $92,84 \%$.

\section{Relação das características anatômicas e teor de extrativos totais da madeira com a qualidade da colagem}

Na Tabela 3 apresentam-se as correlações obtidas pelo teste de Correlação de Pearson, entre as características anatômicas e o teor de extrativos totais da madeira em estudo e a qualidade das juntas coladas com adesivo resorcinol-formaldeído quanto à resistência ao cisalhamento e percentagem de falhas na madeira.

Os parâmetros anatômicos que foram significativos, segundo o coeficiente de Pearson, para a correlação destes com a resistência ao cisalhamento foram: diâmetro do vaso, espessura da parede da fibra, largura e o comprimento da fibra e largura do raio. Estes parâmetros influenciaram positivamente a resistência ao ensaio de cisalhamento, ou seja, quanto maior foi o valor médio do parâmetro anatômico em questão, maior foi a resistência da junta colada ao cisalhamento.

A dimensão do diâmetro do vaso pode facilitar a entrada do adesivo na célula fazendo com que este interaja com a mesma e forme uma maior aderência entre os dois elos e, consequentemente, a ligação se torna mais forte e aumenta a resistência ao esforço de cisalhamento. Porém, vasos com dimensões de diâmetro muito altas podem ocasionar linha de cola faminta e, consequentemente, baixa resistência ao produto colado. 
TABELA 3: Coeficiente de correlação de Pearson entre as características anatômicas e teor de extrativos totais da madeira de Eucalyptus grandis com a qualidade das juntas coladas com adesivo resorcinol-formaldeído quanto à resistência ao cisalhamento e percentagem de falhas na madeira.

TABLE 3: Pearson's correlation coefficient between the anatomical features and the content of extractives of Eucalyptus grandis and the quality of bonded joints with resorcinol-formaldehyde adhesive on the shear strength and the percentage of failures in the wood.

\begin{tabular}{lcc}
\hline Características da madeira & Resistência ao cisalhamento & Falha na madeira \\
\hline Diâmetro do vaso & $0,6867^{* *}$ & $-0,683$ \\
Frequência de vaso & $-0,5849$ & $0,5306^{* *}$ \\
Altura do raio & $-0,2333$ & $0,096^{* *}$ \\
Largura do raio & $0,1939^{* *}$ & $-0,3379$ \\
Frequência de raio & $-0,2959$ & $0,2623^{* *}$ \\
Largura de fibra & $0,5289^{* *}$ & $-0,401$ \\
Espessura da parede da fibra & $0,5784^{* *}$ & $-0,5337$ \\
Espessura do lume da fibra & $-0,3162$ & $0,3936 * *$ \\
Comprimento de fibra & $0,4476^{* *}$ & $-0,4692$ \\
Extrativos totais & $0,5423^{* *}$ & $-0,6129$ \\
\hline
\end{tabular}

Em que: $* *=$ Significativo a $1 \%$ de probabilidade pelo teste $\mathrm{t}$ de Student.

Em relação à largura e ao comprimento da fibra e à largura do raio, estes se comportam da mesma maneira que o diâmetro do vaso, assim, quanto maior a largura da fibra e do raio, maior será a penetração do adesivo na célula e, consequentemente, maior será a adesão entre os dois substratos e maior será a resistência da linha de cola ao esforço de cisalhamento.

Lima et al. (2007) estudaram a influência das características anatômicas sobre a qualidade de colagem de clones de eucalipto e encontraram que a frequência de vasos, frequência e largura dos raios influenciam na colagem da madeira em relação à resistência ao cisalhamento. E, em relação à percentagem de falhas na madeira, os autores encontraram que o diâmetro do vaso influenciou tal variável.

Para a correlação dos parâmetros anatômicos e percentagem de falhas na madeira, foi significativa a frequência de vasos, a espessura do lume da fibra, a frequência e a altura do raio. Sendo que, a correlação foi positiva entre os parâmetros anatômicos em questão e a porcentagem de falhas na madeira.

A frequência de vasos está relacionada com a porosidade que se relaciona com a densidade, que influencia na penetração dos adesivos na madeira (Iwakiri, 2005). De acordo com o coeficiente de Pearson $(0,5306)$, para a correlação entre a frequência de vaso e percentagem de falhas na madeira, este indica que quanto maior for a quantidade de vaso presente na madeira maior será a percentagem de falhas da madeira. Tal fato provavelmente ocorreu devido ao adesivo empregado, que é de alta resistência, formando uma linha de cola mais resistente que a própria madeira. $\mathrm{O}$ mesmo ocorreu para a correlação entre a frequência de raios e percentagem de falhas na madeira, cujo coeficiente de Pearson foi de 0,2623.

Em relação à correlação entre a altura de raio e percentagem de falhas na madeira, o coeficiente de Pearson foi muito baixo $(0,096)$, indicando que a altura do raio pouco interfere nesta propriedade.

A espessura do lume da fibra influenciou a percentagem de falhas na madeira segundo o coeficiente de Pearson que foi de 0,3936. À medida que aumenta a espessura do lume das fibras, maior é a penetração do adesivo nas células, o que pode provocar uma linha de cola com uma resistência muito maior do que a própria resistência da madeira, provocando maior percentagem de falhas na madeira.

Encontrou-se para o teor de extrativos totais o coeficiente de Pearson de 0,5423, indicando a influência do teor de extrativos sobre a qualidade de colagem em relação à resistência ao cisalhamento. A correlação foi positiva, ou seja, para este experimento indicou que quanto maior foi a quantidade de 
extrativos totais presentes na madeira, maior foi a qualidade de colagem em relação à resistência ao cisalhamento. Como o processo de colagem da madeira foi feito a frio (temperatura ambiente) a migração dos extrativos para a superfície não pode ter ocorrido. Segundo Marra (1992), quando ocorre a migração dos extrativos, pode acontecer a inativação da superfície, prejudicando o contato adesivo-madeira.

\section{CONCLUSÕES}

As fibras apresentaram comprimento curto, largura estreita e a espessura da parede média. Os vasos apresentaram diâmetro médio, sendo que, estes foram poucos. A altura média dos raios foi extremamente baixa e a largura extremamente fina. A frequência média de raio foi pouco numerosa.

Os parâmetros anatômicos que influenciaram a resistência ao cisalhamento foram: diâmetro do vaso, espessura da parede da fibra, largura e comprimento da fibra e largura do raio.

Para a correlação dos parâmetros anatômicos e percentagem de falhas na madeira foi significativa a frequência de vasos, a espessura do lume da fibra, a frequência e a altura do raio.

$\mathrm{O}$ teor de extrativos totais pode ter influenciado em uma melhor qualidade de colagem em relação à resistência ao cisalhamento.

No sentido medula-casca, a largura e o comprimento das fibras, a espessura da parede das fibras, o diâmetro do vaso, a largura do raio e o teor de extrativos totais apresentaram acréscimo nos valores médios. Os valores médios da resistência ao cisalhamento seguiram a mesma tendência de aumento e percentagem de falha na madeira que apresentou valor inverso. A frequência de vaso, altura do raio, frequência de raio e espessura do lume da fibra apresentaram decréscimo dos valores médios neste sentido.

No sentido posição I-posição III da tora, os valores médios de espessura do lume das fibras, comprimento das fibras, diâmetro dos vasos, frequência de raio, teor de extrativos totais e percentagem de falhas na madeira apresentaram aumento nos valores médios. Os demais parâmetros apresentaram tendência inversa.

\section{AGRADECIMENTOS}

Ao CNPq - Conselho Nacional de Desenvolvimento Científico e Tecnológico.

\section{REFERÊNCIAS BIBLIOGRÁFICAS}

AMERICAN SOCIETY FOR TESTING AND MATERIALS. Annual book of ASTM standards: adhesives. Philadelphia, 1994. 600 p. D-3110. Standard specification for adhesives used in nonstructural glued lumber products.

AMERICAN SOCIETY FOR TESTING AND MATERIALS. Annual book of ASTM standards: adhesives. Philadelphia, 2000. 600 p. D2339-98. Standard test method for strength properties of adhesives in two-ply wood construction in shear by tension loading.

ASSOCIAÇÃO BRASILEIRA DE PRODUTORES DE FLORESTAS PLANTADAS. Anuário estatístico da ABRAF: ano base 2008. Brasília: ABRAF, 2009. $120 \mathrm{p}$.

ASSOCIAÇÃO BRASILEIRA TÉCNICA DE CELULOSE E PAPEL. Métodos de ensaio. São Paulo: ABTCP, 1974. 18 p.

BURGER, M. L.; RICHTER, H. G. Anatomia da madeira. São Paulo: Nobel, 1991. 224 p.

DELLA LUCIA, R. M.; VITAL, B. R. Avaliação da qualidade de juntas coladas de madeira de três espécies de Eucalyptus. Revista Árvore, Viçosa, v. 5, n. 2, p. 172-180, 1981.

DELLA LUCIA, R. M.; VITAL, B. R. Ensaio de adesão das madeiras de Eucalyptus gummifera, E. paniculata e E. resinifera. Revista Árvore, Viçosa, v. 13, n. 1, p. 98-106, 1989.

FAMER, R. M. Handbook of hardwoods. London: Her Majesty's Stationery Office, 1972. 244 p.

FOREST PRODUCTS LABORATORY. Wood handbook: wood as an engineering material. Madison, WI: U.S. Department of Agriculture Forest Service - Forest Products Laboratory, 1999.

FRANKLIN, G. L. Preparation of thin sections of synthetic resins and wood- resin composites, and a new macerating method for wood. Nature, London, v. 155, n. 3924, p. 51, 1945.

INTERNATIONAL ASSOCIATION OF WOOD ANATOMISTS. List of microscopic features for hardwood identification. IAWA Bulletin, Leiden, v. 10, n. 3, p. 219-332, 1989.

IWAKIRI, S. (Ed.). Painéis de madeira reconstituída. Curitiba: FUPEF, 2005. 247 p.

LIMA, C. K. P. et al. Características anatômicas e químicas da madeira de clones de Eucalyptus e sua influência na colagem. Cerne, Lavras, v. 13, n. 2, p. 123-129, 2007.

LIMA, C. K. P. et. al. Colagem da madeira de clones de Eucalyptus com três adesivos comerciais. 
Scientia Forestalis, Piracicaba, v. 36, n. 77, p. 7377, mar. 2008.

LOBÃO, M. S.; GOMES, A. Qualidade da adesão de madeira de eucalipto em corpos-de-prova colados em dois diferentes planos e densidades. Cerne, Lavras, v. 12, n. 2, p. 194-200, abr./jun. 2006.

MARRA, A. A. Technology of $\operatorname{wood}$ bonding: principles and practice. New York: Van Nostrand Reinhold, 1992. 453 p.

NASCIMENTO, A. M.; DELLA LUCCIA, R. M.; VITAL, B. R. Colagem de emendas biseladas em madeiras de Pinus spp. e Eucalyptus citriodora. Floresta e Ambiente, Rio de Janeiro, v. 8, n. 1, p. 44-51, 2001.

SERPA, P. N. Avaliação da madeira de Eucalyptus grandis W. Hill ex Maiden, Eucalyptus saligna Smith e Pinus elliottii Engelm. para a produção de móveis. 2001. 82 f. Dissertação (Mestrado em Ciência Florestal) - Universidade Federal de Viçosa, Viçosa, 2001.

SILVA, J. C. et al. Influência da idade e da posição ao longo do tronco na composição química da madeira de Eucalyptus grandis W. Hill ex Maiden. Revista Árvore, Viçosa, v. 29, n. 3, p. 455-460, 2005.

SKEIST, I. Handbook of adhesives. New York: Van Nostrand Reinhold, 1990. 778 p.

TOMAZELLO FILHO, M. Estrutura anatômica da madeira de oito espécies de eucalipto cultivadas no Brasil. IPEF, Piracicaba, v. 29, n. 29, p. 25-36, abr. 1985.

TRUGILHO, P. F.; LIMA, J. T.; MORI, F. A. Correlação canônica das características químicas e físicas da madeira de clones de Eucalyptus grandis e Eucalyptus saligna. Cerne, Lavras, v. 9, n. 1, p. 066-080, 2003.

VITAL, B. R.; MACIEL, A. S.; DELLA LUCIA, R. M. Qualidade de juntas coladas com lâminas de madeira oriundas de três regiões do tronco de Eucalyptus grandis, Eucalyptus saligna e Pinus elliottii. Revista Árvore, Viçosa, v. 30, n. 4, p. 637 644, 2006. 